3 Young GB, Lee D. A critique of ancillary tests for brain death. Neurocrit Care 2004; 1: 499-508.

4 Young GB, Shemie SD, Doig CJ, Teitelbaum J. Brief review: the role of ancillary tests in the neurological determination of death. Can J Anesth 2006; 53: 6207.

5 Geeraerts T, Cheisson G, Vigue B. Physiopathologie de la mort encéphalique. Dans: SFAR, SRLF, Agence de la Biomédecine, France (Eds). Prise en Charge des Sujets en État de Mort Encéphalique dans l'Optique du Prélèvement d'Organes et de Tissus. Paris: Elsevier; 2005: 61-8.

\section{Survey of attitudes of anesthesiologists to peripheral nerve blocks}

To the Editor:

The issue of potential risk to patients receiving peripheral nerve blocks is of great importance. Brull et al. ${ }^{1}$ recently published an estimate of neurological risk related to regional anesthesia and observed rates as low as 0.03 per 100 , following supraclavicular block, to an alarming 2.84 per 100 , after interscalene block. Yet, despite this significant risk, Brull et al. ${ }^{2}$ reported that only $58 \%$ of academic anesthesiologists performing regional anesthesia routinely disclose the risks of permanent neuropathy to their patients undergoing continuous nerve block; and only $43 \%$ of the anesthesiologists surveyed disclosed the risk of paralysis.

As a group, anesthesiologists are clearly the most familiar with the potential risks and benefits of regional anesthesia. However, often patients are incompletely informed about potential complications. ${ }^{1}$ Proper, informed consent is imperative; as we cannot assume patients have the same risk tolerance as do anesthesiologists. The analysis of the risk/benefit ratio takes into consideration many factors, such as the patient's pain tolerance and the expected intensity of postoperative pain.

Concern regarding the incidence of neuropathy, and other complications related to peripheral nerve blocks, led us to conduct a survey of our department members. We sought to assess our specialty's attitudes about regional anesthesia. Specifically, we evaluated our acceptance of peripheral nerve blocks for patients and compared that to our acceptance of similar techniques for ourselves, if undergoing a surgical procedure.

Following Research Ethics approval, a survey was circulated by mail to all anesthesiologists at four academic hospitals in Ottawa. Of the 83 surveys sent, 59 were completed (response rate $71 \%$ ). The Table
TABLE Anesthesiologists' acceptance of peripheral nerve blocks for patients and for themselves

\begin{tabular}{|c|c|c|}
\hline Peripheral nerve block & $\begin{array}{l}\text { Number (\%) } \\
\text { of anesthesiologists } \\
\text { who perform } \\
\text { each block } \\
(n=59)\end{array}$ & $\begin{array}{l}\text { Number (\%) } \\
\text { of anesthesiologists } \\
\text { who would decline } \\
\text { each block for } \\
\text { themselves }(n=59)\end{array}$ \\
\hline Interscalene & $45 \quad(76)$ & $(8)$ \\
\hline Supraclavicular & $14 \quad(23)$ & $15 \quad(25)$ \\
\hline Infraclavicular & $14 \quad(23)$ & $10 \quad(16)$ \\
\hline Axillary & $32 \quad(54)$ & $(8)$ \\
\hline Elbow & $7 \quad(11)$ & $10 \quad(16)$ \\
\hline Wrist & $15 \quad(25)$ & $7 \quad(11)$ \\
\hline $\begin{array}{l}\text { Intravenous regional } \\
\text { anesthesia }\end{array}$ & $49 \quad(83)$ & (11) \\
\hline Psoas compartment & $(0)$ & $22 \quad(37)$ \\
\hline Femoral & $51 \quad(86)$ & $6 \quad(10)$ \\
\hline Proximal sciatic & $10 \quad(16)$ & $13 \quad(22)$ \\
\hline Popliteal & $26 \quad(44)$ & $4 \quad(6)$ \\
\hline Ankle & $39 \quad(66)$ & $(15)$ \\
\hline
\end{tabular}

summarizes the principal results. Responders had a wide range of clinical anesthesia experience (from one to over $20 \mathrm{yr}$ in practice). Of the 59 who responded, $12(20 \%)$ rarely, if ever, performed blocks; $36(61 \%)$ performed one to five blocks/month; six (10\%) performed six to ten blocks/month; and only five $(8 \%)$ performed $>$ ten blocks/month. The Table shows the types of peripheral nerve blocks administered by anesthesiologists in our institutions. When questioned about being a block recipient, 36\% of respondents were happy to receive all blocks; $61 \%$ indicated they would decline one or more blocks; and 3\% would refuse all blocks. The main blocks causing concern were lumbar plexus psoas compartment, proximal sciatic, and supraclavicular blocks, which are also the least frequently performed blocks on patients at our institutions. The most common reasons given by anesthesiologists for refusing a peripheral nerve block included: risk of injury to lung, blood vessels, or other structures (63\%); risk of nerve injury $(44 \%)$; and the expected discomfort from nerve block placement $(22 \%)$. Of lesser concern were: local anesthetic toxicity (5\%); injury to, or from, an insensate limb (5\%); and infection $(0 \%)$.

Few studies have addressed anesthesiologists' attitudes and preferences relating to anesthesia techniques for themselves. ${ }^{3}$ This survey demonstrates that a large proportion of anesthesiologists are willing to accept the potential risks of peripheral nerve blocks. 


\section{Alan Lane MB FCARCSI}

Elizabeth Renehan MD FRCPC

Holly Evans MD FRCPC

The Ottawa Hospital, General Campus, Ottawa, Canada

E-mail: alantlane@yahoo.co.uk

Accepted for publication November 28, 2007.

\section{References}

1 Brull R, McCartney CJ, Chan VW, El-Beheiry H. Neurological complications after regional anesthesia: contemporary estimates of risk. Anesth Analg 2007; 104: 965-74.

2 Brull R, McCartney CJ, Chan VW, et al. Disclosure of risks associated with regional anesthesia: a survey of academic regional anesthesiologists. Reg Anesth Pain Med 2007; 32: 7-11.

3 Katz J. A survey of anesthetic choice among anesthesiologists. Anesth Analg 1973; 52: 373-5.

\section{Post-dural puncture postural vertigo}

To the Editor:

Our institution recently admitted a 39-yr-old woman with a diagnosis of acute meningitis. A diagnostic lumbar puncture, undertaken with a 22G Quincke needle, confirmed the diagnosis of acute, aseptic, lymphocytic meningitis [(lymphocytes: $81 \%$ of 420 cells $\mathrm{mm}^{-3}$, neutrophils $3 \%$, other cells $16 \%$ ) glucose $2.7 \mathrm{mmol} \cdot \mathrm{L}^{-1}$ (normal range 2.2-5.0), protides 1.53 (normal range $\left.\left.0.10-0.40 \mathrm{~g} \cdot \mathrm{L}^{-1}\right)\right]$. The patient received acyclovir, amoxicillin, paracetamol and tramadol for four days. However, despite rapid improvement, she was still complaining of vertigo, vomiting and persistent headache four days later. A second lumbar puncture performed at this time showed a reduced, cerebrospinal fluid (CSF) lymphocyte count [(lymphocytes $54 \%$ of 126 cells $\mathrm{mm}^{-3}$, neutrophils $23 \%$, other cells $23 \%$ ), glucose $2.9 \mathrm{mmol} \cdot \mathrm{L}^{-1}$, protides $0.82 \mathrm{~g} \cdot \mathrm{L}^{-1}$ ].

On the fifth day after admission, the patient was apyretic, complaining only of postural vertigo. While vertigo was absent with bed rest, she was unable to walk or stand because of bursting attacks of postural vertigo. A cranial computed tomography scan was unremarkable and a consulting neurologist excluded the possibility of toxic vertigo or a complication of meningitis. While the patient continued with bed rest, her vertigo did not resolve. On the tenth day after admission, her vertigo persisted without any headache. Rapid head movement did not initiate symptoms as in classical positional vertigo. An anesthesiologist was consulted to discuss the possibility of a complication of the lumbar puncture. Examination revealed a discrete right hypoacousia, and the possibility of post-dural puncture vertigo was entertained. The patient consented to having an epidural blood patch, which was performed uneventfully. An 18G Tuohy needle was advanced into the epidural space at the L3-L4 level under aseptic conditions. Only 12 $\mathrm{mL}$ of autologus blood was injected, slowly, as the patient had complained of lumbar tension (with no real back pain), at the end of the injection. Two hours later the vertigo had completely resolved. At one-week follow-up, the patient reported by phone that she had resumed her normal activities of daily living, without vertigo. Although her hypoacousia had improved, it had not fully resolved.

Postural headache is the common manifestation of CSF leakage. ${ }^{1}$ This type of headache is usually associated with a cohort of symptoms including vertigo, nausea, vomiting, hearing loss, and tinnitus. ${ }^{2}$ In some cases, one of these symptoms predominates, masking the headache. ${ }^{3}$ Exceptionally, one of these symptoms is the unique expression of the CSF leakage. ${ }^{4}$ Classical symptoms of CSF leakage were absent on the tenth day following the diagnostic lumbar puncture in this case. However, vestibulocochlear dysfunction, in the setting of post-dural puncture, might require longer than the headache to resolve. ${ }^{3}$ In this particular case, we suspect that the vertigo was probably of vestibular origin, as it was associated with a right hypoacousia. ${ }^{5}$ Drug-induced vertigo may be implicated with tramadol (9.4\% of cases) and rarely, with acyclovir. However, at the time the blood patch was performed, both drugs had been discontinued for five days. Furthermore, the efficacy of the blood patch in this case argues against drug toxicity as a mechanism.

In conclusion, severe and disabling postural vertigo may present as a unique manifestation of persistent CSF leakage after a lumbar puncture, and an epidural blood patch may be effective in treating this complication.

Paul J. Zetlaoui MD

Stéphanie Gibert MD

Olivier Lambotte MD

Hôpital de Bicêtre, France, Le Kremlin-Bicêtre, France

E-mail: paul.zetlaoui@bct.aphp.fr

Accepted for publication December 6, 2007.

\section{References}

1 Candido KD, Stevens RA. Post-dural puncture headache: pathophysiology, prevention and treatment. Best Pract Res Clin Anaesthesiol 2003; 17: 451-69. 